\begin{tabular}{|c|c|c|c|}
\hline \multirow{2}{*}{$\begin{array}{r}\text { Case Reports in } \\
\text { Gastroenterology }\end{array}$} & \multicolumn{2}{|c|}{ Case Rep Gastroenterol 2017;11:120-126 } & \multirow[b]{2}{*}{$\begin{array}{l}\text { Karger } \\
\text { Open access }\end{array}$} \\
\hline & $\begin{array}{l}\text { DOI: } 10.1159 / 000457788 \\
\text { Published online: Varch 3, } 2017\end{array}$ & $\begin{array}{l}\text { (C) } 2017 \text { The Author(s)Published by S. } \\
\text { Karger AG, Basel } \\
\text { www.karger.com/crg }\end{array}$ & \\
\hline & $\begin{array}{l}\text { This article is licensed under } \\
\text { International License (CC BY-N } \\
\text { Usage and distribution for comm }\end{array}$ & $\begin{array}{l}\text { nons Attribution-NonCommercial } \\
\text { ger.com/Services/OpenAccessLicense) } \\
\text { uires written permission. }\end{array}$ & \\
\hline
\end{tabular}

\title{
Eosinophilic Pancreatitis: A Rare Cause of Recurrent Acute Pancreatitis
}

\author{
Jennifer Reppucci Michael Chang Steven Hughes Xiuli Liu \\ Department of Pathology, Immunology, and Laboratory Medicine, University of Florida, \\ Gainesville, FL, USA
}

\section{Keywords}

Eosinophils · Eosinophilic pancreatitis · Recurrent acute pancreatitis

\begin{abstract}
Eosinophilic pancreatitis is a rare form of recurrent acute pancreatitis that demonstrates distinct histologic features, including diffuse, periductal, acinar, and septal inflammatory infiltrates comprised of a pure or predominant population of eosinophils, eosinophilic phlebitis and arteritis, and localized eosinophilic infiltrates with pseudocyst formation. It is associated with elevated serum immunoglobulin E levels, an elevated eosinophil count with systemic manifestations, and eosinophilic infiltrates in other organs of the gastrointestinal tract. We present a case of eosinophilic pancreatitis in a 44-year-old man who was diagnosed after pancreatic resection for recurrent bouts of acute pancreatitis. While the gross and histologic evaluations matched other reported cases of eosinophilic pancreatitis, our patient had only minimal peripheral eosinophilia, no reported history of symptoms related to elevated eosinophilia or immunoglobulin $\mathrm{E}$, and only mild eosinophilic infiltrates in his gallbladder.
\end{abstract}

(C) 2017 The Author(s)

Published by S. Karger AG, Basel

\section{Introduction}

Eosinophilic pancreatitis (EP) is a rare form of pancreatitis, with very few cases reported in the literature. It is usually not diagnosed until the patient undergoes pancreatic resec- 


\section{Case Reports in Gastroenterology}

Case Rep Gastroenterol 2017;11:120-126 DOI: 10.1159/000457788

(c) 2017 The Author(s). Published by S. Karger AG, Basel www.karger.com/crg

Reppucci et al.: Eosinophilic Pancreatitis: A Rare Cause of Recurrent Acute Pancreatitis

tion. EP demonstrates distinct histologic patterns: diffuse, periductal, acinar, and septal inflammatory infiltrates comprised of a pure or predominant population of eosinophils, eosinophilic phlebitis and arteritis, and localized intense eosinophilic infiltrates associated with pseudocyst formation [1]. These histologic features are typically associated with elevated serum immunoglobulin E levels, an elevated eosinophil count with systemic manifestations, and eosinophilic infiltrates in other organs of the gastrointestinal tract [1].

We present a case of EP in a patient with recurrent bouts of acute pancreatitis previously thought to be related to familial hypertriglyceridemia. While the gross and histologic evaluations matched other reported cases of EP, our patient had only minimal peripheral eosinophilia, no reported history of symptoms related to elevated eosinophilia or immunoglobulin E, and only mild eosinophilic infiltrates in his gallbladder.

\section{Case Report}

Our patient was a 44-year-old man with a past medical history significant for recurrent bouts of acute pancreatitis with no definite etiology. The patient denied a history of drug and alcohol use but did admit to smoking half a pack of cigarettes per day. He was allergic to shellfish. He had multiple pancreatic duct stents placed for pancreatic duct leak; the most recent stent was removed in June 2016. He presented to the Emergency Department at University of Florida Health and Shands Hospital (Gainesville, FL, USA) on July 31, 2016, with worsening epigastric pain for 10 days. The patient reported that he had been pain free for approximately 30-45 days after the stent was removed in June, but then the pain returned. He described the pain as sharp and radiating to the back with nausea and vomiting. The inciting etiology for his pancreatitis was thought to be familial hypertriglyceridemia.

A computed tomography of the abdomen and pelvis showed prominence of the main pancreatic duct with a luminal diameter ranging up to $4.0 \mathrm{~mm}$, presumably related to the patient's recent bouts of pancreatitis. Coarse calcification was seen at the pancreatic head, but there was no evidence of acute inflammatory stranding around the pancreas. No pseudocyst was seen. A stone was visualized in the nondistended gallbladder. There was mild prominence of the proximal loops of the jejunum, which was most likely due to an inflammatory ileus. Labs on admission were significant for a lipase of 1,079 U/L (reference: 13-60 $\mathrm{U} / \mathrm{L}$ ) and elevated absolute eosinophil count of $0.6 \times 10^{3} / \mu \mathrm{L}$ (reference: $0.3-0.46 \times 10^{3} / \mu \mathrm{L}$ ). The ALT, AST, total bilirubin, direct bilirubin, alkaline phosphatase, white blood cell count, and eosinophil count were all within normal reference ranges. However, lab results approximately $8 \mathrm{~h}$ after admission showed elevated triglycerides of $235 \mathrm{mg} / \mathrm{dL}$ (reference: 55-149 $\mathrm{mg} / \mathrm{dL}$ ), an eosinophil count of $8.5 \%$ (reference: $0-8 \%$ ), and an absolute eosinophil count of $0.53 \times 10^{3} / \mu \mathrm{L}$ (reference: $0.3-0.46 \times 10^{3} / \mu \mathrm{L}$ ).

The patient's symptoms rapidly improved with intravenous fluids, nothing by mouth, and pain medication. He was able to progress his diet within $4 \mathrm{~h}$ and tolerate it. The pancreaticobiliary surgery team decided to perform a cholecystectomy and pancreatic drainage procedure at a later date. The patient was discharged on August 2, 2016, and then presented for an outpatient follow-up exam with the pancreaticobiliary surgery team on August 23, 2016. He subsequently returned to our institution on August 25, 2016, and underwent a scheduled modified Frey procedure and cholecystectomy.

The pancreatic specimen consisted of a firm segment of pancreatic head that was pinktan, lobular, and measured $2.0 \times 2.0 \times 1.0 \mathrm{~cm}$. The gallbladder was relatively small, measuring $3.5 \mathrm{~cm}$ in greatest dimension, and did not contain any stones. Microscopic examination of 


\section{Case Reports in Gastroenterology}

Case Rep Gastroenterol 2017;11:120-126 DOI: 10.1159/000457788

(c) 2017 The Author(s). Published by S. Karger AG, Basel www.karger.com/crg

Reppucci et al.: Eosinophilic Pancreatitis: A Rare Cause of Recurrent Acute Pancreatitis

the gallbladder exhibited nonspecific chronic inflammation with focal mild eosinophilia. The pancreatic head showed patchy atrophy of acini and extensive inter- and intra-lobular fibrosis, including focal storiform fibrosis (Fig. 1). There was extensive eosinophilic infiltration in the septa, focally in the acini, and around veins and nerves (Fig. 2a, b). Significant apoptosis and karyorrhexis of eosinophils was noted. The pancreatic duct showed periductal mononuclear cell infiltrate, focal denudation of epithelium, and mild neutrophilic inflammation in the lumen. Proteinaceous material was noted in the main pancreatic duct and rare small ducts. Focal squamous metaplasia was noted in periductal mucous glands. Additionally, a few small veins showed eosinophilic phlebitis, which was highlighted with a Verhoeff-Van Gieson stain (Fig. 3). An IgG4 immunohistochemical stain did not reveal a significant number of IgG4positive plasma cells. A CD117 (c-Kit) immunohistochemical stain revealed scattered mast cells but no evidence of mastocytosis. A diagnosis of EP was rendered, along with a recommendation for clinical correlation with peripheral blood eosinophilia, immunoglobulin IgE levels, and IgG4 levels, as well as a potential response to steroid treatment. IgG4 results on September 6, 2016, were $38 \mathrm{mg} / \mathrm{dL}$, which fell within the reference range of 1-123 mg/dL. Postoperative recovery was complicated by hypotension, altered mental status, and a hematoma, all of which ultimately resolved. The patient was discharged home on September 11, 2016. At outpatient follow-up 15 days later, no complications were observed.

\section{Discussion}

EP is a rare form of pancreatitis, with very few cases reported in the literature. It is usually not diagnosed until the patient undergoes pancreatic resection. A few reports have shown that this condition can mimic a pancreatic neoplasm, thus prompting surgical intervention; however, this was not the case with our patient [1-4]. The mechanism by which eosinophils are involved in this form of pancreatitis has not been elucidated; however, the possibility that eosinophils may elicit pancreatitis due to a direct toxic effect via cytotoxic and proinflammatory mediators has been considered [5].

EP demonstrates distinct histologic patterns: diffuse, periductal, acinar, and septal inflammatory infiltrates comprised of a pure or predominant population of eosinophils, eosinophilic phlebitis and arteritis, and localized intense eosinophilic infiltrates associated with pseudocyst formation [1]. These histologic features are typically associated with elevated serum immunoglobulin E levels, an elevated peripheral eosinophil count with systemic manifestations, and eosinophilic infiltrates in other organs of the gastrointestinal tract $[1,4]$. However, according to Abraham et al. [1], these features are not universally present and patients may have a normal eosinophil count with localized EP, without other organ involvement.

The correct diagnosis of EP is important because it can occur in conjunction with eosinophilic gastroenteritis or hypereosinophilic syndrome. EP without eosinophilic gastroenteritis is rare, and it may be helpful to suggest further biopsies of the gastrointestinal tract [3]. Hypereosinophilic syndrome is a potentially fatal condition that manifests with peripheral eosinophilia of 1,500 eosinophils $/ \mathrm{mm}^{3}$ for more than 6 months, no evidence of secondary eosinophilia, and signs of organ involvement, most commonly in the heart [3]. Both of these conditions are responsive to steroid therapy.

The differential diagnosis for eosinophils in the pancreas is extensive and includes conditions such as lymphoplasmacytic sclerosing pancreatitis (LPSP, also known as autoimmune pancreatitis), pancreatic allograft rejection, inflammatory myofibroblastic tumor, sys- 
temic mastocytosis, and parasitic infection. LPSP (autoimmune pancreatitis) is a more frequently documented condition that can be difficult to distinguish from EP. LPSP has a mostly lymphoplasmacytic infiltrate and generally lacks granulocytes. Other histologic findings include interstitial fibrosis (storiform fibrosis), acinar atrophy, and obliterative phlebitis [6]. Patients with LPSP often have an evenly enlarged ("sausage-like") pancreas, while those with EP will usually have enlargement of only the pancreatic head or tail [4]. Patients with LPSP also show elevated IgG4 levels; however, in a recent article by Hart et al. [6], serum and tissue IgG4 abnormalities are considered characteristic but not essential for the diagnosis of LPSP [7]. Myofibroblastic tumors typically have a mixed inflammatory infiltrate. Eosinophils are usually not the predominant inflammatory cell component, and there should be a prominent spindle cell component [3].

Despite few documented cases in the literature, the correct diagnosis of EP is important because it can be treated with steroids, $40-60 \mathrm{mg}$ daily, potentially curing the patient of their recurrent attacks and avoiding unnecessary surgical intervention. Nonsteroid alternatives, such as cromolyn, montelukast, hydroxyurea, azathioprine, and ketotifen, have been used with positive therapeutic effects as well [5]. Appropriate treatment can prevent future development of the associated conditions, eosinophilic gastroenteritis and hypereosinophilic syndrome. In these patients, follow-up with eosinophil count, immunoglobulin E, and biopsies of other gastrointestinal sites may be warranted.

\section{Statement of Ethics}

The authors have no ethical conflicts to disclose.

\section{Disclosure Statement}

The authors have no conflicts of interest to declare.

\section{References}

1 Abraham SC, et al: Eosinophilic pancreatitis and increased eosinophils in the pancreas. Am J Surg Pathol 2003:27:334-342.

-2 Cay A, Imamoglu M, Cobanoglu U: Eosinophilic pancreatitis mimicking pancreatic neoplasia. Can J Gastroenterol 2006;20:361-364.

-3 Euscher E, et al: Eosinophilic pancreatitis: a rare entity that can mimic a pancreatic neoplasm. Ann Diagn Pathol 2000;4:379-385.

4 Tian L, Fu P, Dong X, Qi J, Zhu H: Eosinophilic pancreatitis: three case reports and literature review. Mol Clin Oncol 2016;4:559-562.

5 Lyngbaek S, Adamsen S, Aru A, Bergenfeldt M: Recurrent acute pancreatitis due to eosinophilic gastroenteritis. Case report and literature review. JOP 2006;7:211-217.

-6 Hart PA, Smyrk TC, Chari ST: Lymphoplasmacytic sclerosing pancreatitis without IgG4 tissue infiltration or serum IgG4 elevation: IgG4-related disease without IgG4. Mod Pathol 2015;28:238-247.

7 Matsubayashi H, et al: Diagnosis of autoimmune pancreatitis. World J Gastroenterol 2014;20:1655916569. 


\section{Case Reports in Gastroenterology

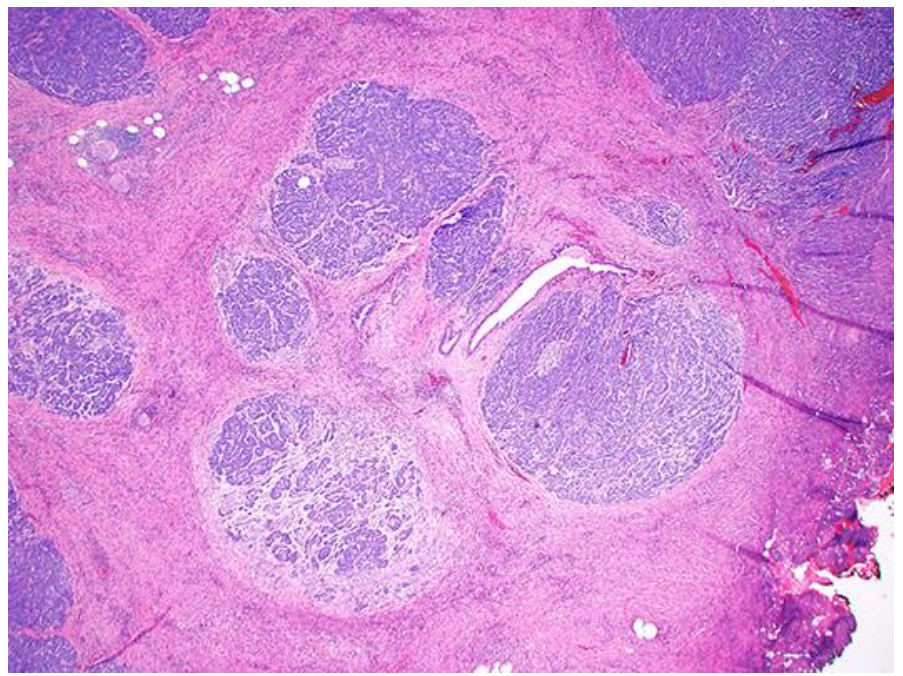

Fig. 1. Pancreatic head demonstrates atrophy of acini and extensive inter- and intra-lobular fibrosis, including focal storiform fibrosis. HE stain. $\times 20$ magnification. 


\section{Case Reports in Gastroenterology}

\begin{tabular}{l|l}
\hline Case Rep Gastroenterol 2017;11:120-126 \\
\hline DOI: 10.1159/000457788 & $\begin{array}{l}\text { @ 2017 The Author(s). Published by S. Karger AG, Basel } \\
\text { www.karger.com/crg }\end{array}$ \\
\hline
\end{tabular}

Reppucci et al.: Eosinophilic Pancreatitis: A Rare Cause of Recurrent Acute Pancreatitis

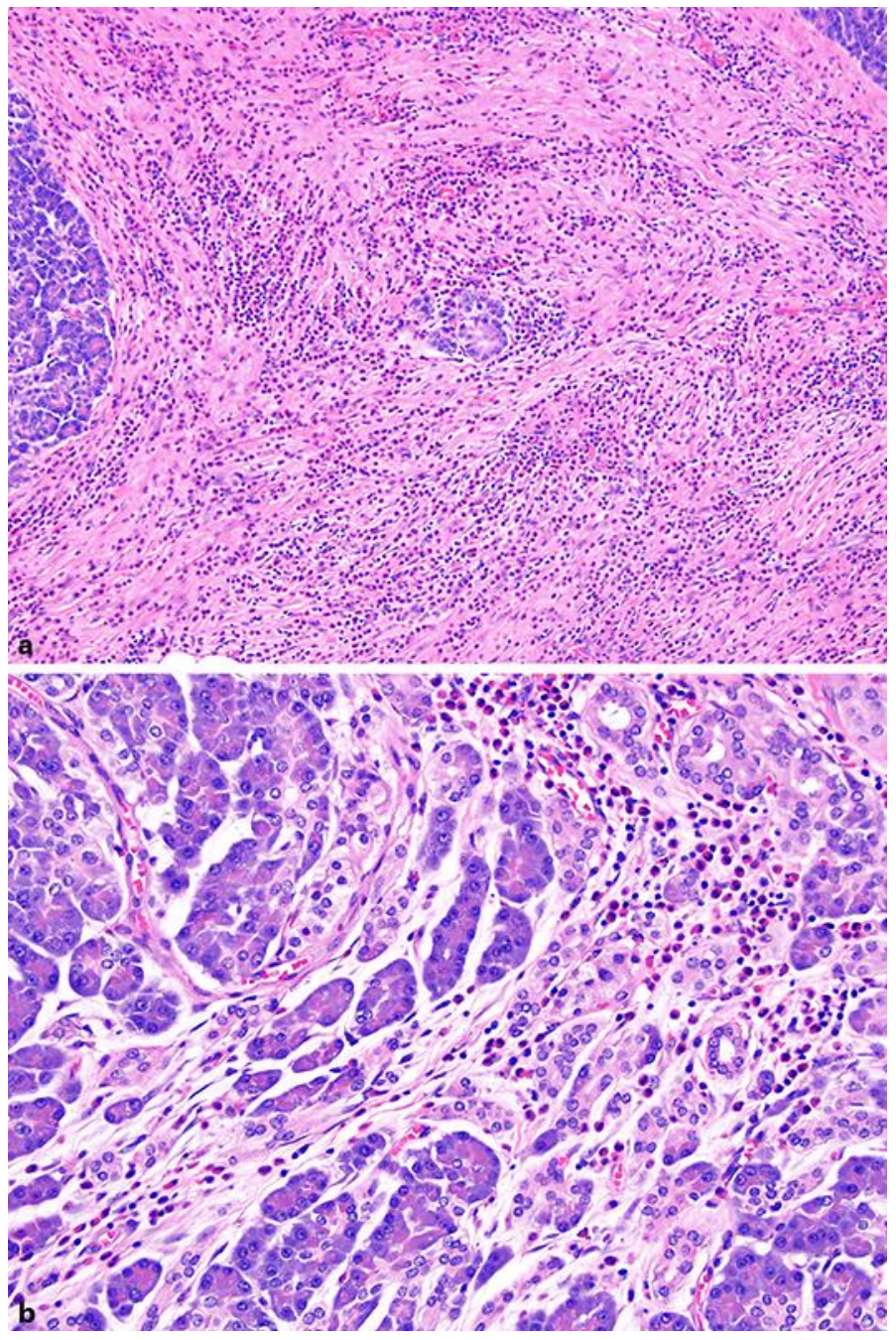

Fig. 2. a Pancreatic head with extensive eosinophilic infiltration of fibrotic septa. HE stain. $\times 100$ magnification. b Pancreatic head with eosinophilic infiltration of pancreatic acini. HE stain. $\times 200$. 


\begin{tabular}{|c|c|c|}
\hline \multirow{3}{*}{$\begin{array}{r}\text { Case Reports in } \\
\text { Gastroenterology }\end{array}$} & \multirow{2}{*}{\multicolumn{2}{|c|}{ Case Rep Gastroenterol 2017;11:120-126 }} \\
\hline & & \\
\hline & DOI: $10.1159 / 000457788$ & $\begin{array}{l}\text { ( ) } 2017 \text { The Author(s). Published by S. Karger AG, Basel } \\
\text { www.karger.com/crg }\end{array}$ \\
\hline
\end{tabular}

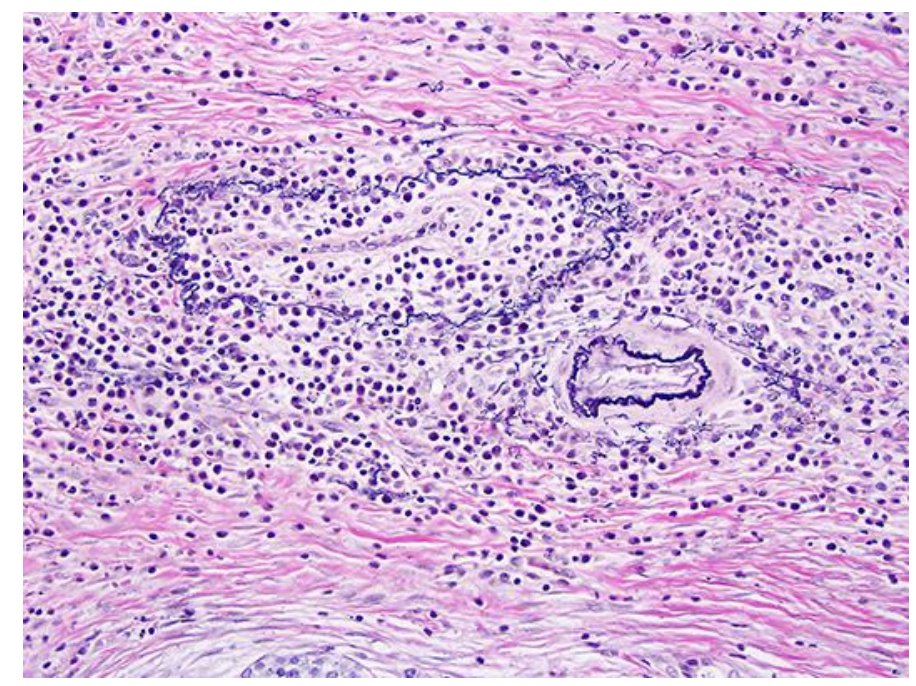

Fig. 3. Verhoeff-Van Gieson stain highlights eosinophilic phlebitis of small veins. HE stain. $\times 200$ magnification. 